\title{
Presentation of Binning-Based Inter-Click Interval Data from Passive Acoustic Monitoring of Free- Ranging Harbour Porpoises (Phocoena Phocoena)
}

\author{
Maximilian Ruffert \\ School of Mathematics \& Maxwell Institute, University of Edinburgh, EH9 3FD, UK.
}

\author{
Victoria L. G. Todd \\ Ocean Science Consulting, Spott Road, Dunbar, Scotland, EH42 1RR, UK. \\ School of Media Arts and Technology, Southampton Solent University, East Park Terrace, Southampton SO14 OYN, \\ $U K$.
}

\author{
Ian B. Todd \\ Ocean Science Consulting, Spott Road, Dunbar, Scotland, EH42 1RR, UK.
}

(Received 13 December 2018; accepted 26 April 2019)

C-PODs are used for Passive Acoustic Monitoring (PAM) of harbour porpoises (Phocoena phocoena) at an offshore open sea location in the German North Sea.

Diel patterns of echolocation click trains are extracted from minimum inter-click interval (minICI) data by binning. The aim of this study is to reassess and refine minICI ranges of click train data with particular consideration to the binning widths. Emphasis is also placed on choosing an appropriate visualisation of these binned data.

Key ecological results include presence of higher train rates during the day with intermediate minICI values defined by the range 6-28 $\mathrm{ms}$ and a higher train rate with short minICI values $1.25-2.00 \mathrm{~ms}$ at night. This indicates an increase in porpoise feeding behaviour, or change of style, at night. Click trains with long minICI values $>$ $35 \mathrm{~ms}$ occur at an equal rate throughout both diel phases, suggesting a more routine behaviour, such as navigation.

Results could be revealed only by judicious choice of binning widths, e.g. previously overlooked patterns within historical echolocation data. The classification methodology can be used to analyse echolocation trains from a variety of species and can be applied to any PAM data with the relevant click parameters.

\section{INTRODUCTION}

\subsection{Measurement of Animal Echolocation Sounds}

Echolocation is the deliberate production of sounds to generate echoes off biotic and abiotic features in the environment, and has evolved independently in several taxa including toothed cetaceans, ${ }^{1}$ bats, ${ }^{2}$ shrews, ${ }^{3}$ tenrecs ${ }^{4}$ and cave-dwelling birds $^{5}$ (see Thomas ${ }^{6}$ for a review). Harbour porpoises (Phocoena phocoena) are small toothed cetaceans that emit Narrow Band High Frequency (NBHF) communication and echolocation clicks almost constantly, ${ }^{7,8}$ and can be collected with a range of underwater Passive Acoustic Monitoring (PAM) systems. ${ }^{9,10}$ One example of a static (non-towed) PAM device is the C-POD (Chelonia UK), which has become increasingly popular because it is accurate, ${ }^{11}$ robust, can be left in situ for many months (March 2018 record: 338d:09h:24m, Todd, V.L.G., unpublished observations), thus covering diel, tidal, and seasonal cycles, ${ }^{12,13}$ and contains automatic processing software (C-POD.exe) which reduces signal analyses time significantly. ${ }^{14} \mathrm{C}$-PODs (and their analogue predecessor, T-PODs), have been used widely to study many odontocete species, including inter alia, harbour porpoises. ${ }^{15,16}$

C-PODs are described in the available literature. ${ }^{11} \mathrm{C}-\mathrm{POD}$ click-train recognition algorithms filter out non-cetacean clicks and give reliable data on cetacean presence and echolocation behaviour by using digital waveform characterisation to select and log time of cetacean tonal ultrasonic sounds from 120-160 $\mathrm{kHz}$. In addition, they also log centre frequency, intensity, and bandwidth of each cetacean click.

One of several data parameters readily exportable from CPOD software is the inter-click interval (ICI), also sometimes referred to as inter-pulse interval. The ICI is a numerical value measured in seconds (s) or milliseconds (ms), defined as "the temporal separation of clicks emitted by the same vocalising animal". ${ }^{17}$ For an informative review on ICIs used by odontocete species, see Dunn. ${ }^{18}$ Harbour porpoise ICIs vary between $1.5-200 \mathrm{~ms}^{19}$

For technical and practical extraction of minICI, refer to the C-POD manual. ${ }^{14} \mathrm{~A}$ description is given in Carlström. ${ }^{20}$ For brevity, key procedures are summarised here. The C-POD logs data for every click detected, including time, duration, frequency, and sound pressure level. These individual clicks are collected into separate trains. Each train can be analysed and classified, e.g. probable species class and quality of data. Time 
intervals between individual clicks are determined within every train, and the minimum of these intervals — ignoring the error-prone first and last clicks — is logged as minICI.

\subsection{Interpretation of Echolocation Sound Measurements}

Pioneering studies in bats and dolphins discovered that when an animal waits for the echo from the target, before generating the next click, ICI correlates with distance to the target. ${ }^{2,21} \mathrm{~A}$ recent study has shown that porpoises use their acoustic 'gaze' by adjusting their ICIs to glean a sharp picture of both near and possible further targets. ${ }^{22}$ A relationship between ICI and behaviour has been observed in odontocetes. ${ }^{23}$

Griffin ${ }^{24}$ identified changes in ICI over three distinct foraging phases: (1) search phase, characterised by regular ICIs, (2) approach phase, where ICIs decrease steadily with decreasing target range, and (3) terminal phase, where immediately prior to target capture, ICI intervals decrease such that clicks resembled a 'buzz'. In odontocetes, the 'terminal buzz' occurs before attempted or successful prey capture ${ }^{25}$ therefore, in acoustic studies were visual verification of behaviour is not possible, ICI can be used as a proxy to infer foraging behaviour. ${ }^{12,26}$

Porpoises are small cold-water predators, that are known to live on an energetic knife-edge, hunting small fish nearly continuously day and night with extreme capture rates, ${ }^{27}$ so ICI is an effective and reliable value to use in analysis of porpoise data.

\subsection{Visual Presentation of Inter-click Interval Data}

Historically, ICI data have been presented visually in a variety of plot types. For example, simple bar graphs have been used effectively to display the relationship between inferred foraging and diel cycle. ${ }^{12}$ ICI has also been modelled with temporal and environmental parameters, ${ }^{28}$ or plotted with two way travel time to provide a proxy for distance to a target. ${ }^{19}$ ICI data are presented most commonly as histograms, which display ICI frequency divided into specific bin widths; however, it has not been acknowledged widely in the literature that choice of bin width can have a large influence on relationships inferred visually from histograms. A small bin width yields an irregularly shaped histogram with the appearance of large variance, whereas a large bin creates an over-smoothed histogram where important patterns might be overlooked; ${ }^{29}$ therefore, it is fundamental to select a bin width which displays the essential structure of the data set. ${ }^{30}$

ICI histogram bin widths differ vastly throughout literature, even within the same species of interest. For example, studies on harbour porpoise have used bin widths of $2 \mathrm{~ms}^{20,36}$ and $10 \mathrm{~ms} .{ }^{31}$ Moreover, numerous papers omit to state selected bin width, or fail to justify bin width chosen. In order to visualise patterns and relationships in ICI data effectively, bin widths must be adjusted to reflect the required level of detail and ICI range in the species of interest. For example, an ICI equal to, or less than $10 \mathrm{~ms}$ is often used as a proxy for feeding in harbour porpoises; ${ }^{12,20}$ however, Verfu $\beta^{19}$ found harbour porpoises emit clicks at a constant ICI of 1.4-1.6 ms during the

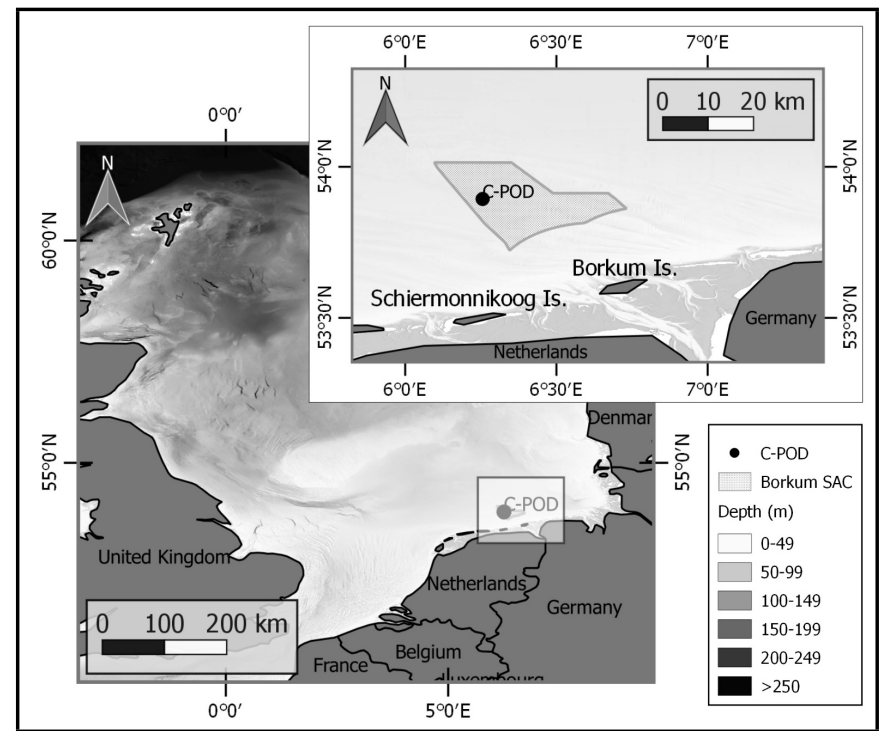

Figure 1. Chart of the North Sea. The circle marks C-POD deployment location. SAC='Special Area of Conservation'

terminal buzz. Consequently, a bin size of $10 \mathrm{~ms}$ or larger would fail to distinguish patterns of ICIs of $<10 \mathrm{~ms}$.

This paper explores the effect of altering histogram bin widths to elucidate potentially hidden patterns in ICI data and presents a novel approach in this context to compare data visually by displaying multiple histograms within the same plot. This procedure is useful for highlighting temporal patterns across diel, tidal, or seasonal cycles and for facilitating visual comparison between different stages of these cycles. Using free-ranging, open sea, harbour porpoise C-POD echolocation click-data, we explore diel patterns in ICIs and adjust histogram bin widths to pinpoint specific and repeated ICI values, and the characteristic of terminal buzzes.

\section{METHODOLOGY}

\subsection{Data Collection}

Between 2 December 2009 and 2 January 2010, a C-POD on standard default settings (Table 1) logged harbour porpoise echolocation click train data, on a featureless seabed without any nearby structures, at an offshore location of the Borkum Riffgrund region, in the German North Sea, as shown on Fig. (1). The dataset obtained from a C-POD is used for the fine-scale analysis in this paper.

At a hydrophone depth of $30 \mathrm{~m}$ and a seabed depth of $32 \mathrm{~m}$ (at lowest astronomical tide), the low-profile and sub-surface acoustic release mooring used for the C-POD is designed for manual deployment and to minimise any reef effects while at the same time minimising interference with porpoise echolocation behaviour. ${ }^{32}$ The streamlined mooring design is intended to minimise any turbulence and flow noise, to maximise signalto-noise ratio, and thereby to maximise porpoise acoustic detections.

Version 2.026 of CPOD.exe was used for data export, display, and fully automated detection and classification of click trains, for which only 'high' and 'moderate' quality and 'NBHF' (porpoise) species were selected for a reliable data analysis. C-POD data were processed solely for NBHF click 
Table 1. List of C-POD settings.

\begin{tabular}{||l|l|}
\hline Quantity & setting \\
\hline Hysteresis & 90 \\
\hline Min SPL & 1 \\
\hline Max SPL & 12 \\
\hline StSPL & 1 \\
\hline BW threshold & 30 \\
\hline Min duration/F & 3 \\
\hline Mins to end & 1333333 \\
\hline HR intercept & 0 \\
\hline Low bias & 0 \\
\hline High bias & 255 \\
\hline St min & 30 \\
\hline St max & 250 \\
\hline Setup file version & 1 \\
\hline Trigger & off \\
\hline No clicks & 5 \\
\hline SPL & 200 \\
\hline kHz start & 100 \\
\hline kHz end & 80 \\
\hline Min cycles & 3 \\
\hline Alerting device & off \\
\hline kHz & 120 \\
\hline Bandpass filter $(\mathrm{kHz})$ & 20 \\
\hline Gain (fixed) & - \\
\hline
\end{tabular}

trains, considered as harbour porpoise, to minimise the number of false-positive detections. All click trains produced by this post-processing, subject to the choice of classes above, were then used for the following analysis. No other re-classification, e.g. minimum or maximum interval periods between click trains or additional clustering of trains, was considered.

\subsection{Data Analysis}

Astronomical timings for sunset (SS) and sunrise (SR) and civil twilight (CT) dawn and dusk, were taken from the United States Naval Observatory 2015 tables. ${ }^{33}$ Given the coordinates of a geographical position, the USNO website provides calendars in tabular form of SS, SR and CT times. These tables were copied by simple cut-and-paste from the web page into Microsoft Excel, where the format was changed. From a traditional monthly table format, we produce (using manipulations by hand) a double list of SS/SR and CT times indexed by dayof-the-year numbers. This was output as a txt file and read into the computing environment Matlab (version R2017b). We then recalculated these SS/SR and CT vectors in the given format of time-of-day as a function of day-of-year into the format minute-number-since-start-of-1900 (referred to as MN) which was used by the C-POD software (C-POD guide, ${ }^{14}$ Section 'Times'). This latter transform is most easily done using the POD data themselves: pick a random click train, read off the exact date and time of day and its associated $\mathrm{MN}$, and from this obtain an internally consistent value for the shift between the selected click train and all SS/SR and CT numbers in the vectors.

The duration of the four diel phases (a subdivision of a $24 \mathrm{~h}$ period), was calculated by taking the appropriate differences between the SS/SR and CT values for every day, as specified by the diel definitions of the four phases. ${ }^{12}$ Using the minutenumber format described above yields the values shown in

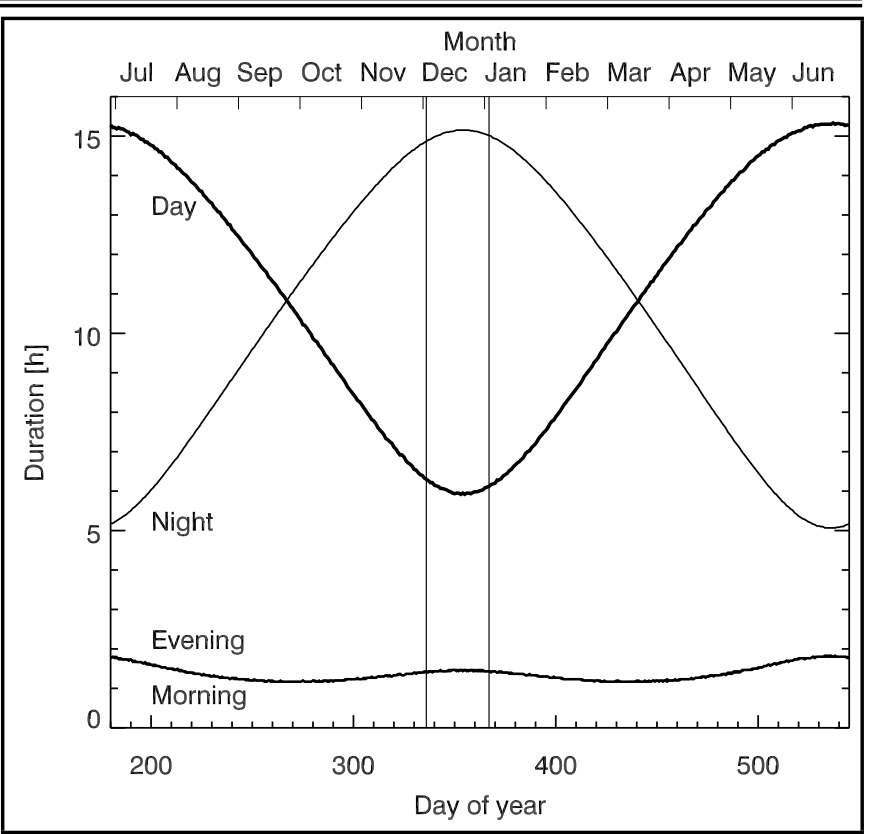

Figure 2. Duration of the diel phases as function of the day of the year. The two vertical lines indicate beginning and end of the monitoring period (2 Dec. and 2 Jan.).

Fig. (2). Duration of the diel day as a function of date and day-of-year was shown and similarly for the diel night, morning and evening. Notice how for this geographical site, nights were longest (approx. $15 \mathrm{~h}$ ) and symmetrically the days shortest (approx. $6 \mathrm{~h}$ ) during the monitoring period 2 December to 2 January. Note also how the duration of diel phases morning and evening varied between approx. $1 \mathrm{~h}$ and $2 \mathrm{~h}$ over the course of the year and is approx. $1.5 \mathrm{~h}$ during the monitoring period.

The method of analysis is described exemplarily using Fig. (3) as an illustration. Every click train has associated with it, inter alia plethora other characteristics, time and date it was logged and the minICI of clicks in a train. The numerical computing environment Matlab (R2017b) was used to count the number of trains with particular values for the chosen characteristics.

The first filter considered only trains which were logged during a particular diel phase. Given the date and time of a train, this characteristic was compared to values in the double vector list generated above, and a decision then made as to during which diel phase (e.g. day) a train occurred.

The second filter allocated the train to a multiple of a particular chosen interval, called bin size $b$, of its minICI value. Bin sizes can in principle be chosen to be of any value, but should be small compared to minICI values of interest. Since feeding buzzes included minICI values of $10 \mathrm{~ms}$ (see Discussion section 4 for further details), the choice $b=0.25 \mathrm{~ms}$ is a sensible example. The filter consists of assigning a bin to the train by calculating the fraction $\min I C I / b$, taking its integer value $n$ and adding 1 to the bin counter $n$. Hence $n=0$ denotes the first bin which commences at a minICI value of 0 and goes up to, but does not include $b$, e.g. $0-0.25 \mathrm{~ms}$. The next bin this example would span $0.25-0.5 \mathrm{~ms}$. The number of trains counted in the first bin produces the horizontal piece of line in the plot starting at $x=0$ and ending at $x=0.25$ point. The next value in the second bin produces a short line piece starting at 


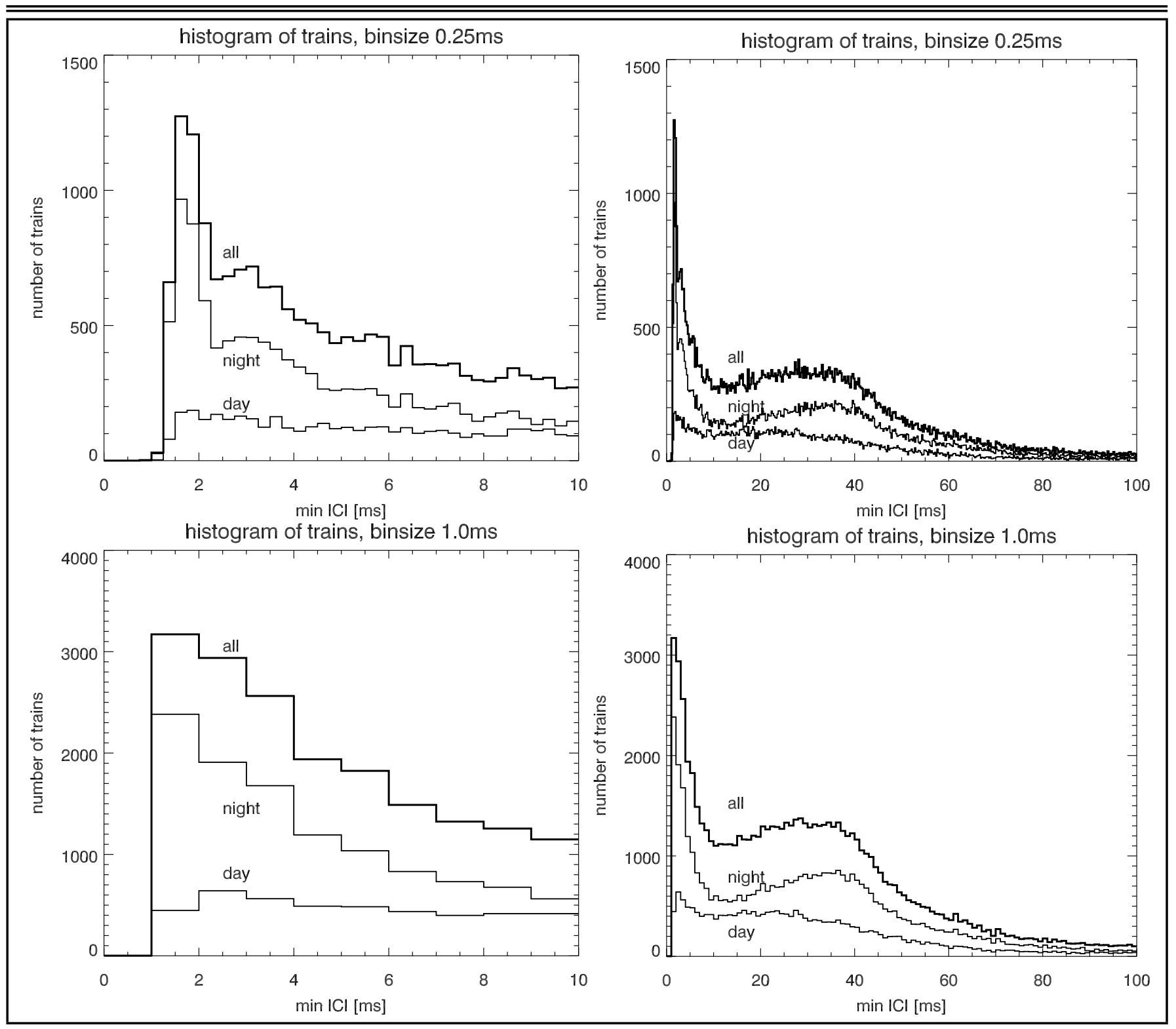

Figure 3. Number of click trains as a function of minimum inter-click interval (minICI), divided into the diel phases, night and day. The curve labelled 'all' shows the sum of the number of all trains during all four diel phases, for that particular bin. The range on the minICI $x$-axis is either $0-10 \mathrm{~ms}$ (left panels) or 0-100 ms (right panels). The bin size is either $0.25 \mathrm{~ms}$ (top panels) or $1.0 \mathrm{~ms}$ (bottom panels). The piecewise horizontal lines reflects the bin spacings, see main text.

$x=0.25$ and ending at $x=0.5$ and so forth.

Following this methodology, it was possible to plot the number of trains within a particular diel phase as a function of minICI, using a particular bin size, achieved in various ways. A bin size of $b=0.25 \mathrm{~ms}$ was used to generate the top two plots in Fig. (3). Since the number plotted corresponded actually to the whole interval, it represents a natural way to plot these values is with horizontal lines. These piecewise constant lines are connected by vertical straight lines to produce a continuous curve. An alternative presentation would be to use bars, not presented here, as overlaying bars within one plot is problematic to display clearly.

Data were also analysed using mean ICI and maximum ICI instead of minICI (for exact definitions see C-POD user guide, 2014), to address the risk of outliers. Trains are broken up as porpoises move their heads side-to-side during foraging (i.e. when off-axis, trains appear broken). Consequently, minimal differences were found between results from minimum, mean and maximum ICI, showing that the inclusion of truncated trains in the minICI analysis has insignificant effects on results.

\section{RESULTS}

\subsection{Dataset and Diel Phases}

During the 32-day deployment period, a C-POD logged ca. 82,000 porpoise echolocation trains. As described in previous sections, these were subdivided into defined diel phases and into various minICI bins and number of trains in each subset counted and plotted.

\subsection{Echolocation Click Train Data}

Figure (3) presents minICI data divided into diel phases. The three curves represent 'all' $(24 \mathrm{~h})$, diel day and diel night. The 'all' curve equals the sum of all four diel phases. The 
morning and evening transitional periods exhibited more fluctuations since they comprised a much smaller number of trains and were therefore excluded from plots. In the top left panel of Fig. (3) the 'all' curve has one maximum peak and two points cover that peak in the range minICI 1.5-2.0 ms, with $n \approx 1300$ and $n \approx 1200$, respectively. This curve represents the number of trains when using a bin size of $0.25 \mathrm{~ms}$. It is also evident from Fig. (3) that there is a marked dominance of the night time for trains of the maximum peak. In the bottom two panels of Fig. (3) bin size is increased to $1.0 \mathrm{~ms}$. This is mirrored by the $y$-axis values being roughly four times larger than in the top plots which have bins of $0.25 \mathrm{~ms}$. The right panels in Fig. (3) extend the $x$-axis to $100 \mathrm{~ms}$. With bin size increased to $1 \mathrm{~ms}$, data fluctuations are now significantly smaller and curves appear smoother. It can be concluded from this example that a fairly large bin size of $1.0 \mathrm{~ms}$ is appropriate to present data in the range out to $100 \mathrm{~ms}$. The bottom left panel in Fig. (3) shows the same $1 \mathrm{~ms}$ bin data, but only over the range for minICI 0 $10 \mathrm{~ms}$. This allowed comparison with the data in the top left panel, where an artificial strong broadening of the curve maximum is observed. Hence a bin size of $1.0 \mathrm{~ms}$ masks interesting details for minICI values in the range $0-3 \mathrm{~ms}$ and is not appropriate for this short range. Consequently, the most appropriate combinations of bin size and minICI range are the ones in the top left and the bottom right panels, which is selected for the following step.

Figure (4) shows two plots which include the $3 \sigma$ (three standard deviations, $\mathrm{P}=99.7 \%$ ) region above and below the curves for the day, night, and all. This is an indication of data fluctuations (assuming a Gaussian distribution) and helps to ascertain whether the number of trains is different statistically during day and night. For example, the regions mildly overlap between approx. 8-20 ms and so the difference is not statistically significant (to $3 \sigma$ ); however, in the region between ca. 25-45 ms, there is a highly significant (ca. $6 \sigma$ ) difference in the number of trains between night and day. Conversely, considering the very short minICI, it is impossible to elucidate anything for the region shorter than $1.25 \mathrm{~ms}$, but in the region $1.25-4 \mathrm{~ms}$, there is again a statistically highly significant difference between night and day (ca. $5 \sigma$ ).

Since data were collected in an uncluttered, open sea environment, distanced from any obstacles, over a flat seabed, multipath signal arrival routes would only be via the surface and although perhaps present, would likely only constitute a small fraction of click and train recordings.

\subsection{Diel Analysis of Short and Long minICI}

Examining the data presented in Fig. (4) more closely, and comparing day and night curves, it can be seen that a larger difference exists between the very short minICI $1.25-2.00 \mathrm{~ms}$ as compared to 2.00-4 ms. Looking further at longer minICI, day and night curves separate again around 30-40 ms. Finally, for very long minICI, say $40-60 \mathrm{~ms}$, the tail of the distribution shows that there were more night trains than day trains, by some constant factor.

Figure (5) investigates and interprets this feature further, by showing the factor for the fraction of the number of night trains

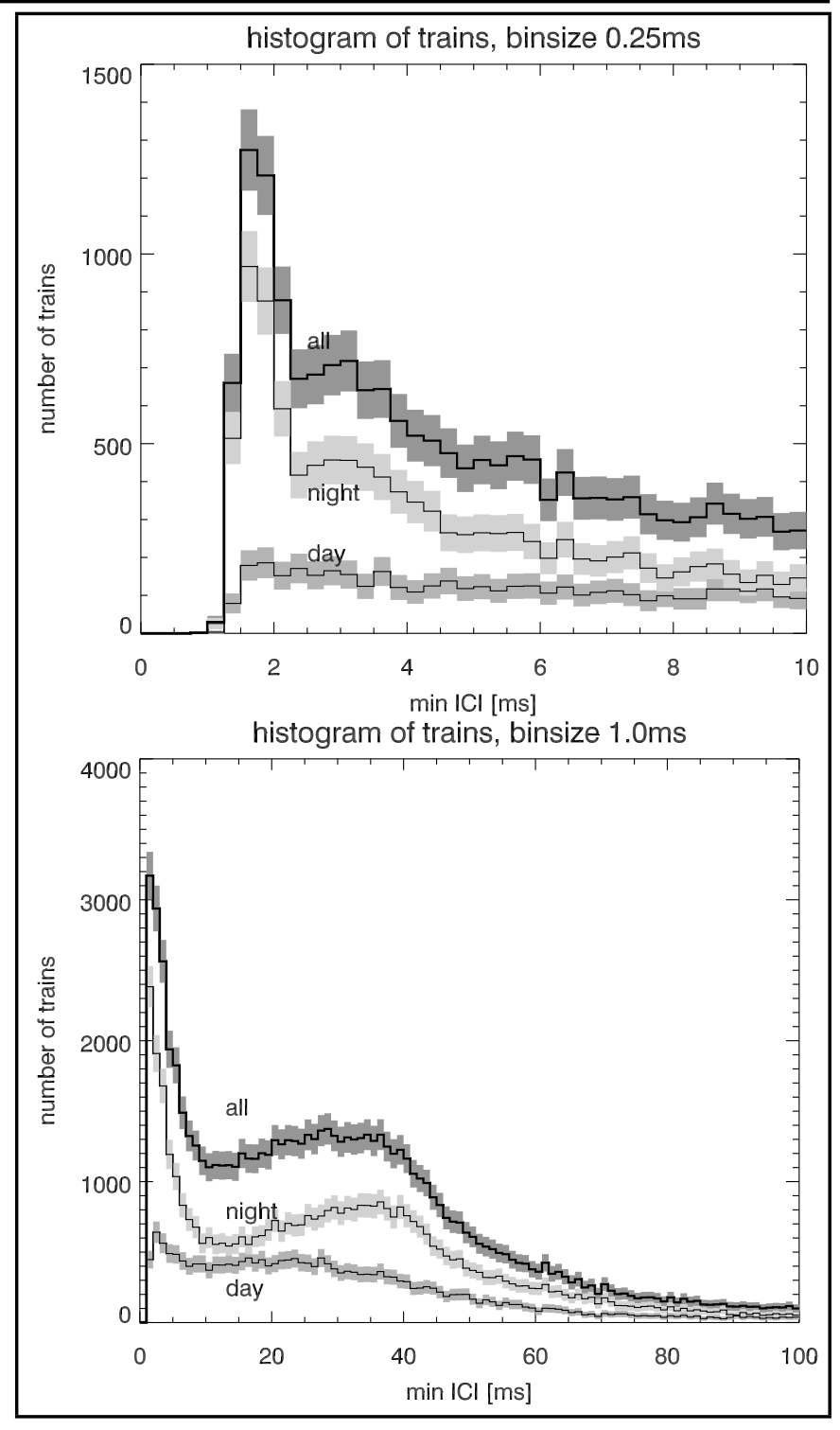

Figure 4. Number of trains as function of minICI. The $\pm 3 \sigma$ (square root) variation are shown as grey shaded areas. Left panel: range $0-10 \mathrm{~ms}$ minICI and bin size $0.25 \mathrm{~ms}$; right panel: range $0-100 \mathrm{~ms}$ minICI and bin size $1.0 \mathrm{~ms}$

divided by the number of day trains, for each bin. The $x$-axis spans a minICI of $0-80 \mathrm{~ms}$ and a bin size of $2.0 \mathrm{~ms}$ was selected to minimise noise, and to facilitate the location of the the 'plateau' at long minICI; consequently, for this plot, the exact size was not important, as it is an intermediate step only to link between plots showing the number of trains and plots showing rates. For the very short minICI of $2 \mathrm{~ms}$, there was a factor of 5.5 more trains during the night. For the long minICI range $40-80 \mathrm{~ms}$, the factor was $2-3$, see Fig. (5). This latter factor range is close to the ratio between the durations of day and night in winter (approx. factor 2.5), during which time these data were collected and hence nothing further should be inferred from this feature other than that longer data collecting times produce a proportionally larger number of trains.

The next quantity focussed on was train rates. Fig. (6) shows rates for minICI ranges of 0-6 ms and 0-60 ms. Bin sizes of $0.25 \mathrm{~ms}$ and $2.0 \mathrm{~ms}$ were chosen respectively, to ensure that comparison for the two cases was meaningful, given the relevant standard deviations. Each value plotted shows the number of trains per minICI bin divided by average length (in min- 


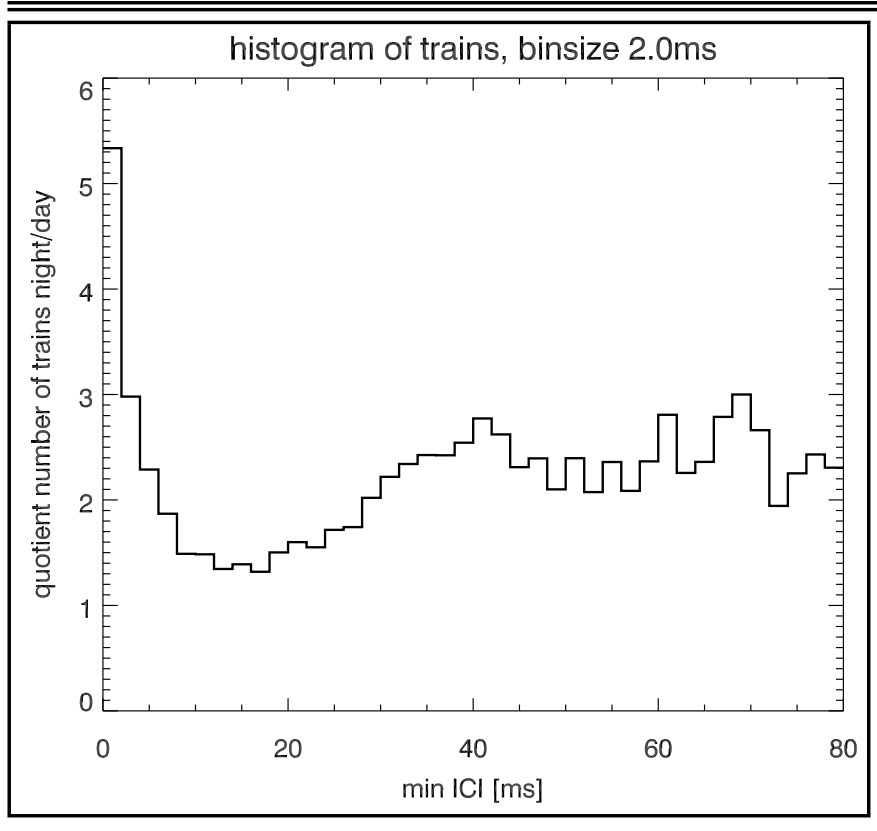

Figure 5. Relative factor, i.e. quotient of number of night trains divided by number of day trains as function of minICI, for the minICI range $0-80 \mathrm{~ms}$ and for bin size $2.0 \mathrm{~ms}$.

utes) of diel day or night. This produces a train rate (number/minute) per bin. In the right panel of Fig. (6), it can be seen that in the 30-60 ms range day and night rates are the same, to within statistical significance $(3 \sigma)$. In 6-28 ms range, trains were emitted at about half the rate during the night than the day. The left panel of Fig. (6) shows that the very rapid click trains with minICI $1.25-2.00 \mathrm{~ms}$ were emitted at a rate which is approximately twice as high at night than the day. Given the $3 \sigma$ regions, which can be inspected in both panels of Fig. (6), it follows that these statements are statistically more significant than $3 \sigma(99.7 \%)$.

\subsection{Statistical Significance Test}

Since the $3 \sigma$ regions were provided in previous plots, visual inspection verifies the statistical significance of descriptions given. Nonetheless, a formal hypothesis test is presented to assess if rates of the two states (night vs. day for various minICI values) differ, based on the assumption that trains are described by a Poisson point process (aka. a purely random process).

Let the night rate $\lambda_{\mathrm{n}}$ be given by the number of trains recorded $(N)$ divided by the duration of the observation $\left(t_{\mathrm{n}}\right)$, and similarly the day rate be given by $\lambda_{\mathrm{d}}=D / t_{\mathrm{d}}$. The standard deviations follow to be $\sigma_{\mathrm{n}}=\frac{\lambda_{\mathrm{n}}}{\sqrt{N}}$ and $\sigma_{\mathrm{d}}=\frac{\lambda_{\mathrm{d}}}{\sqrt{D}}$. Three times these values $\left( \pm 3 \sigma_{\mathrm{d}}\right.$ and $\left.\pm 3 \sigma_{\mathrm{n}}\right)$ are shown in the grey areas in Figs. (4) and (6), and are designated as ' $3 \sigma$ ' in the captions and the main text.

The hypothesis of whether the given (Poisson mean) rates $\lambda_{\mathrm{d}}$ and $\lambda_{\mathrm{n}}$ are equal, given the number of observations and duration of the observations, can be checked by using the appropriate test statistic $Z=\frac{c D-N}{\sqrt{c^{2} D+N}}$, with $c=t_{\mathrm{n}} / t_{\mathrm{d}} \cdot{ }^{34} \mathrm{P}-$ values follow in the usual way from the normal distribution ${ }^{1}$. Technically, the use of erfc, the complementary error function,

${ }^{1}$ Personal communication, Dr. Bruce J. Worton, University of Edinburgh.

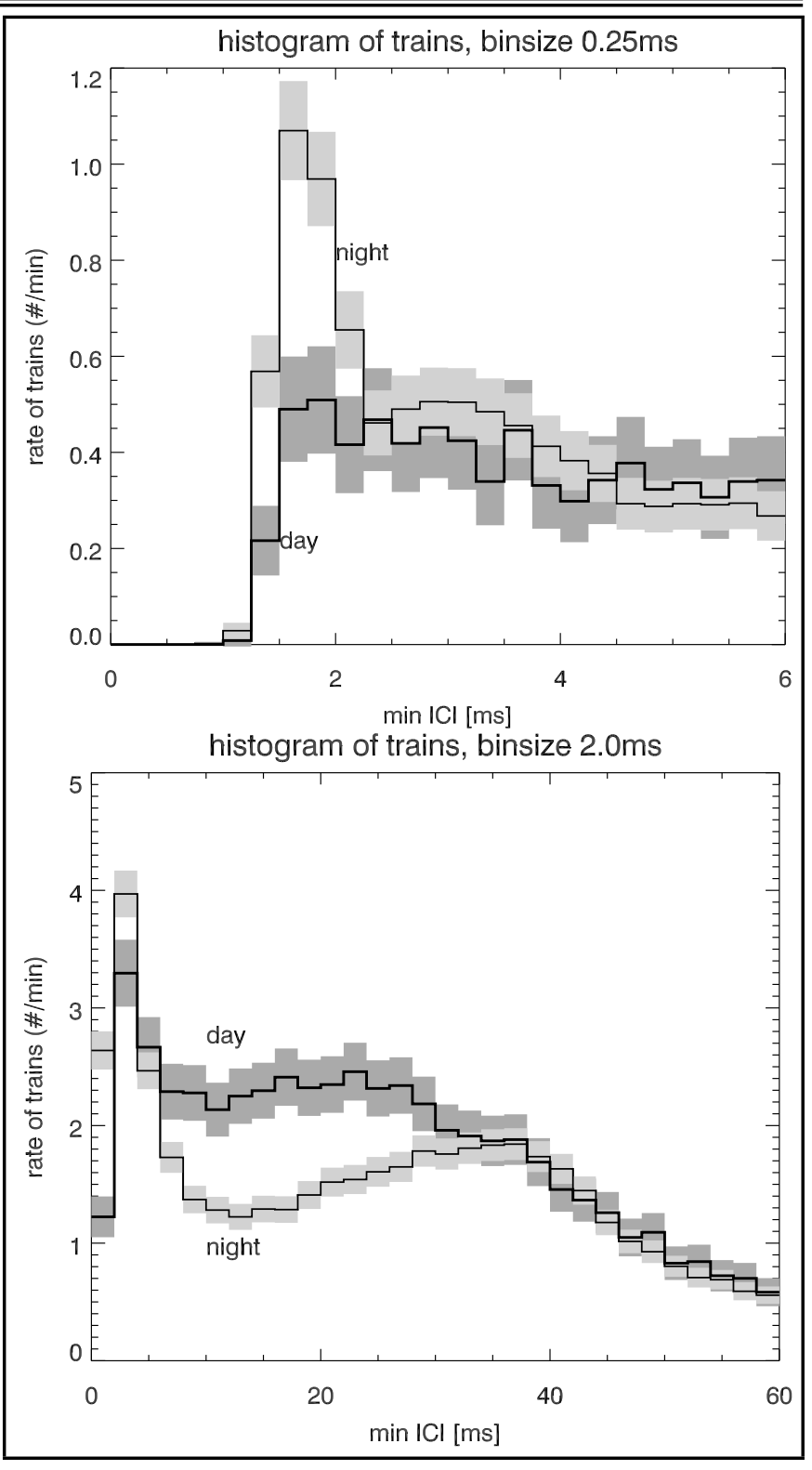

Figure 6. Train rates (number/minute) as function of minICI. The $\pm 3 \sigma$ (square-root) variation are shown as grey shaded regions above and below the lines. Left panel: range $0-6 \mathrm{~ms}$ minICI and bin size $0.25 \mathrm{~ms}$; right panel: range $0-60 \mathrm{~ms}$ minICI and bin size $2.0 \mathrm{~ms}$.

was necessary, due to the extreme function values required, $P=\operatorname{erfc}(Z / \sqrt{2})$.

For each and every bin, this hypothesis testing was performed using the mathematically equivalent test statistic:

$$
Z=\frac{\lambda_{\mathrm{d}}-\lambda_{\mathrm{n}}}{\sqrt{\sigma_{\mathrm{d}}^{2}+\sigma_{\mathrm{n}}^{2}}}
$$

where rates and standard deviations are all taken as relevant individually for each bin. The results are plotted in Fig. (7). Since resulting values are exceedingly tiny, values are shown in a logarithmic (base 10) plot and cut off at a value of -14 , or equivalently, a P-value smaller than $10^{-14}$. This demonstrates that they are highly statistically significant. 


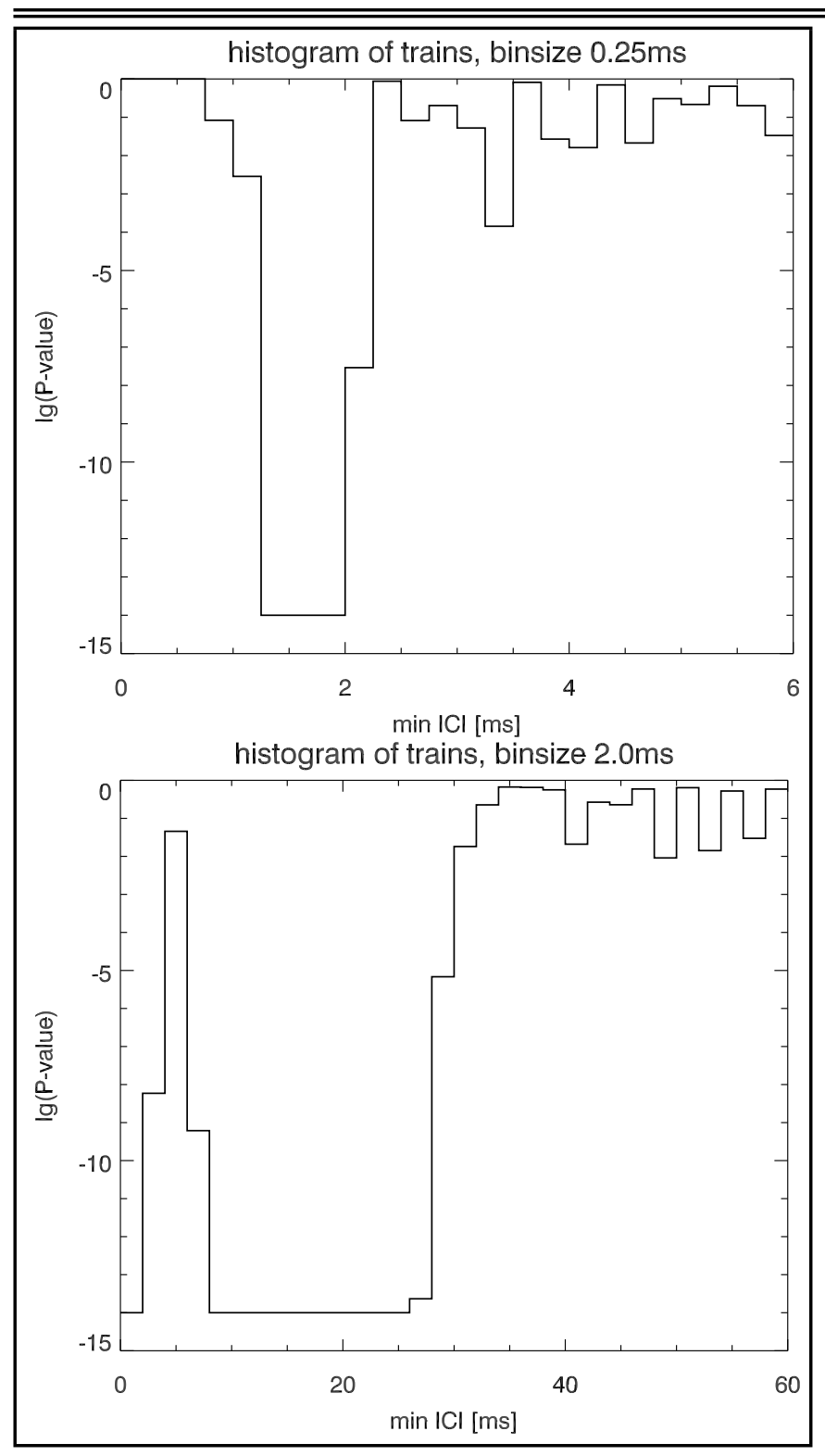

Figure 7. $\mathrm{P}$ values for each minICI bin, evaluating the data presented in Fig. (6). Left panel: range $0-6 \mathrm{~ms}$ minICI and bin size $0.25 \mathrm{~ms}$; right panel: range $0-60 \mathrm{~ms}$ minICI and bin size $2.0 \mathrm{~ms}$. The $\log _{10}(\mathrm{P}$ values $)$ are cut off below -14 for ease of presentation.

\subsection{Variable Bin Sizes Determined by Statistical Significance}

Bin sizes can be determined semi-automatically if the significance level is chosen. As a specific example, select a significance level of $P=0.001$ and using the inverse complementary error function $\mathrm{erfc}^{-1}$ the quantile can be calculated, $z_{p}=\sqrt{2} \operatorname{erfc}^{-1}(P) \approx 3.29$. This allows the construction of confidence intervals $\mu \pm z_{p} \sigma$, where, as usual, $\mu$ is the mean and $\sigma$ the variance of a normal variable. For ease of viewing a graph, this interval is chosen to be $\gamma=10 \%$ of the whole $y$-axis range. Equating both requirements yields the number of data points (trains) per bin, $n_{\text {bin }}=\left(z_{p} / \gamma\right)^{2} \approx 1082$.

MinICI train rates with variable adaptive binning, as shown in Fig. (8), were calculated as follows. After finding minimum ICI values for all trains, these values were sorted from short to long, $t_{j}$. For all possible integers $i$ starting with $i=0$, extract value $t_{k}$ where $k=i \cdot n_{\mathrm{bin}}$. These $t_{k}$ values are the boundaries

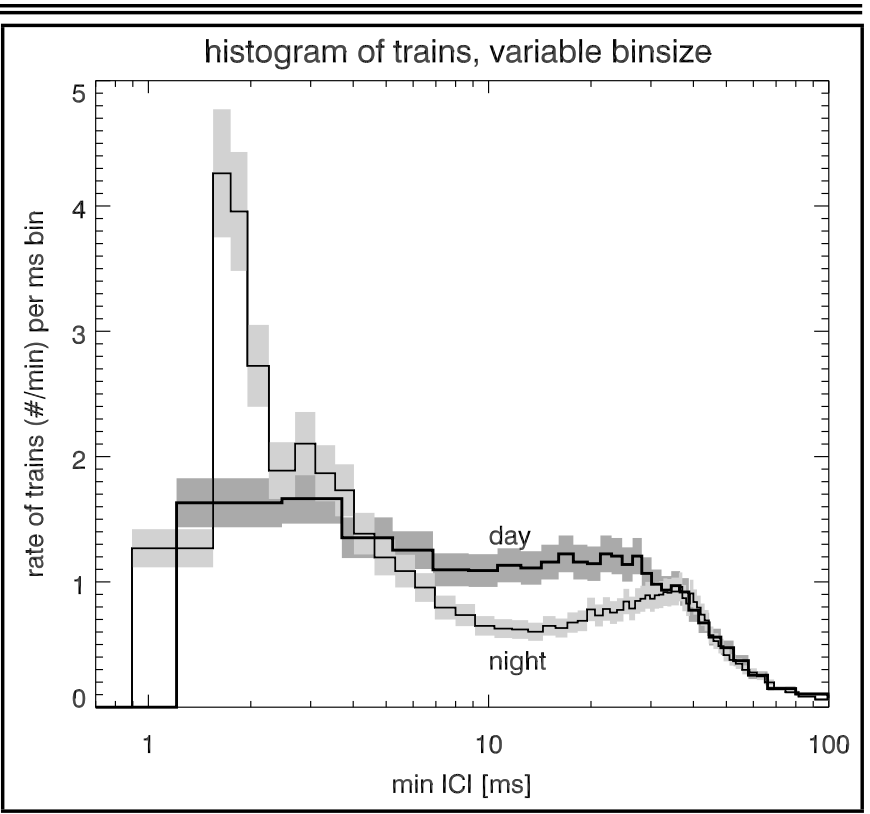

Figure 8. Train rates (number/minute) per ms bin as function of minICI for night and day trains. The grey shaded regions above and below the lines show the $P<0.001$ significance bands. Note logarithmic $x$-axis scale.

for the variable bins indexed by $i$. Each bin was allocated the value $y_{i}=\lambda /\left(t_{i+1}-t_{i}\right)$, where $\lambda=\lambda_{\mathrm{n}}$ or $\lambda=\lambda_{\mathrm{d}}$ depending on whether the night or day rate was plotted (see Sect. 3.4). Note also that bin boundaries $t_{k}$ differ for night and day train subsets.

The procedure outlined above produced bar plots with variable width bars, as can be seen in Fig. (8), e.g. compare bins around $\operatorname{minICI}=2 \mathrm{~ms}$ which have width approx. $0.2 \mathrm{~ms}$ with bins around $\operatorname{minICI}=10 \mathrm{~ms}$ which have width ca. $1 \mathrm{~ms}$. Note that the grey shaded bars in Fig. (8) are ca. $10 \%=\gamma$ of the function values, as per construction. A logarithmic scale for the $x$-axis was chosen to show within the same plot the narrow spike at $\operatorname{minICI} \approx 1.8 \mathrm{~ms}$ and the wide gap at $\operatorname{minICI} \approx 7 \mathrm{~ms}$ to $30 \mathrm{~ms}$.

Ultimately, the information content of Fig. (8) is the same as was presented in Fig. (6), as it should be, since the features are statistically significant; however, recall that for Fig. (6) binwidths choice was determined by judicious judgement, while for Fig. (8) bin widths were determined semi-automatically via the choice of the significance level. This procedure only works well with a sufficient amount of data. If overly stringent significance values are selected, as compared to available data, the proposed procedure yields too few bins and no sensible graph can be generated.

The difference in train rates between day and night can be calculated and compared for trains with short and intermediate minICI, as follows. For trains with short minICIs the difference in rates is approximately 2.5 trains $/ \mathrm{min} / \mathrm{msbin}$, multiplied by the range $0.75 \mathrm{~ms}$ gives approximately 1.9 trains $/ \mathrm{min}$, while for intermediate minICI trains the equivalent estimate is 0.7 trains $/ \mathrm{min} / \mathrm{msbin} \times 22 \mathrm{~ms}=15.4 \mathrm{trains} / \mathrm{min}$. Note that the latter (15.4) is distinctly larger than the former (1.9). 


\section{DISCUSSION}

\subsection{Overview}

In 32 days, ca. 82,000 trains were extracted by C-POD software as 'high' \& 'moderate' quality data on NBHF species, logged and analysed. Different ways to present data were considered, impact of bin size investigated, data noise variation assessed, diel comparisons of trains with shorter minICI values vs. longer minICI values examined, lengths of diel day and night periods taken into account, and train rates discussed. All these quantities were presented as plots. It has been demonstrated that the appropriate choice of bin width must be selected to match the quality of the given data and the features of interest extracted. This is a difficult compromise between small bin sizes to explore detailed features vs. large bin sizes with consequently large data sets and high statistical test confidence levels. Alternatively, given a selected P-value, matching bin sizes can be automatically generated; an example of this procedure was presented.

\subsection{Harbour Porpoise Behaviour}

Analysis of data highlighted the presence of trains with intermediate minICI values during the day and very short minICI values at night. While inferences on porpoise behavioural implications of the data observed are outwith the scope of this paper, the data presented are typical of porpoises in the wild. Previous studies investigating characteristics of harbour porpoise echolocation, both in captivity and in the wild, have reported that variations in click rates and minICI values appear to be correlated strongly with behaviour and habitat usage. ${ }^{16,35}$ Observed differences in click rates and minICI values showed diel changes in harbour porpoise habitat usage within the survey area, and were likely correlated with habitat complexity.

Villadsgaard $^{31}$ and Teilmann ${ }^{36}$ reported minICI values of ca. 50-60 ms. Their results correspond to data presented here, in that for minICI values longer than $40 \mathrm{~ms}$, the day and night rates were similar. The main hypothesised explanation for this consistency in minICI values are environmental factors, e.g. open space with few obstacles in an offshore setting, as opposed to coastal environments with multiple cluttered targets. During the day, harbour porpoises echolocate primarily for navigational and exploration purposes with the reduction in intermediate minICI values $6-28 \mathrm{~ms}$ at night, related possibly to the requirement to look further afield in search of prey. Verfu $\beta^{37}$ and Kastelein ${ }^{38}$ noted a decreasing click rate as harbour porpoises approached a predetermined target, and that multiple shorter click trains were used when tracking smaller targets.

Figures (6) and (8) show that short minICI trains, in the range $1.25-2.00 \mathrm{~ms}$, were recorded most frequently at night. Click trains with minICI of this brevity are reported commonly in the literature as linked to feeding behaviour. ${ }^{39,40}$ Of the six types of social sounds used in different behavioural contexts as described by Amundin, ${ }^{41}$ only the 'S-display sound' has click repetition rates slow enough ( 2550 clicks/s) to be within the minICI range of 6-28 ms observed in this study; the remaining five signals had rates equivalent to an minICI of $5 \mathrm{~ms}$ or less. Clausen ${ }^{42}$ recorded variations in click train characteristics of harbour porpoises in different social situations. A recent study showed a quite high frequency of NBHF trains interpreted as click communication trains rather than echolocation trains. ${ }^{8}$

Rapid changes in click characteristics have been observed when a hunting harbour porpoise is within one to two body lengths of its target. Verfu ${ }^{19}$ reported a decrease in minICI value from $50 \mathrm{~ms}$ to $10 \mathrm{~ms}$ at a distance $<4.4 \mathrm{~m}$. Following the rapid decrease, constant buzz minICI values of around $1.5 \mathrm{~ms}$ to $1.6 \mathrm{~ms}$ have been observed routinely. These buzz rates correspond closely to the minICI values recorded at night during this study, indicating that harbour porpoises are potentially using their echolocation to feed. This corroborates the idea that the reduction in the number of intermediate minICI trains 6$28 \mathrm{~ms}$ at night is linked to the requirement to look further afield for prey, and the rapid click trains recorded in the data in this study set are characteristic of feeding buzzes.

Some other behavioural influences on minICI variation include source-level variations, varying hunting depths and light level changes. Given the depth of the C-POD deployment in this study, if harbour porpoises dive deeper at night, there is a greater chance that the weaker buzz clicks will be detected, ${ }^{43}$ but additional empirical observations are required to check this. Although light conditions can influence harbour porpoise echolocation behaviour, ${ }^{44}$ the increase in shorter ICIs at night, is more likely due to other factors, e.g. the light conditions at $30 \mathrm{~m}$ depth during the day may not be good enough for foraging by vision only.

\section{CONCLUSION}

(1) Diel analysis of echolocation data highlights the presence of trains with three distinct ranges of minICI values: long $>35 \mathrm{~ms}$, intermediate 6-28 ms, and short 1.25-2.00 ms. Statistical tests show very high confidence levels.

(2) Emphasis is placed on choosing the appropriate binning widths and an appropriate visualisation of the binned data. As an alternative to explicitly selecting bin widths a procedure is presented which generates variable bins widths semi-automatically given a selected confidence level; an exemplary plot for $\mathrm{P}=0.001$ is shown.

(3) The two ranges of intermediate and short minICI show diel behavioural patterns in harbour porpoises, as follows. (a) Rates of short minICIs are high at night. (b) Rates of intermediate minICIs are high during the day. (c) Rates for long minICIs are equal during night and day.

(4) For harbour porpoise behavioural patterns, it is suggested that the short minICI range indicates this species feed more at diel night and speculate that intermediate range is linked to exploration and the search for prey further afield during the day.

\section{ACKNOWLEDGEMENTS}

Special thanks to Eric Boon, Mark Spittle and their crew (Noble); Eduard Noormann and his crew (Wasser- und Schifffahrtsverwaltung des Bundes); Hanneke van den Berge, Niels 
Torgau, Christian Busch, Claudia Bärle, and Daniel Richardson (Wintershall); Derek Hutchison and Peter Lugton (Lafarge); Nick Tregenza (Chelonia); Jakob Tougaard and Line Kyhn (Aarhus University); Paul White (Institute of Sound and Vibration Research, Southampton University); Colin MacLeod (Aberdeen University); Petra Todd (OSC). Survey design, fieldwork, and equipment, were funded by OSC, and the analysis was funded jointly by OSC and a Maximaths research grant from Edinburgh University. MR would like to thank Dr. Bruce J. Worton at the School of Mathematics, Centre of Statistics, University of Edinburgh, for explaining how to calculate P values in this context.

\section{REFERENCES}

1 McBride, A. F., "Evidence for echolocation by cetaceans", Deep Sea Res. 54, 437-499, (1956). https://dx.doi.org/10.1016/0146-6313(56)90096-X.

2 Griffin, D. R., "Listening in the dark" Yale University Press, New Haven, CN, (1958).

3 Siemers, B. M., Schauermann, G., Turni, H., and von Merten, S., "Why do shrews twitter? Communication or simple echo-based orientation", Biol. Lett. 5, 593-596, (2009). https://dx.doi.org/10.1098/rsbl.2009.0378.

4 Gould, E., "Evidence for echolocation in the Tenrecidae of Madagascar", Proc. Am. Phil. Soc. 109, 352-360, (1965).

5 Medway, L., "The function of echonavigation among swiftlets", Anim. Behav. 15, 416-420, (1967). https://dx.doi.org/10.1016/0003-3472(67)90038-3.

6 Thomas, J., Moss, C., and Vater, M. (eds), "Echolocation in bats and dolphins", The University of Chicago Press, Chicago, USA, (2004). ISBN 978-0-226795-99-7.

7 Akamatsu, T., Teilmann, J., Miller, L. A., Tougaard, J., Dietz, R., Wang, D., Wang, K., Siebert, U., and Naito, Y., "Comparison of echolocation behaviour between coastal and riverine porpoises", Deep Sea. Res. Pt. II. 54, 290-297, (2007). https://dx.doi.org/10.1016/j.dsr2.2006.11.006.

8 Sørensen, P. M., Wisniewska, D. M., Jensen, F. H., Johnson, M., Teilmann, J., Madsen, P. T., "Click communication in wild harbour porpoises (Phocoena phocoena)", Sci. Rep. 8, 9702 (2018). https://dx.doi.org/10.1038/s41598-01828022-8

9 Todd, V. L. G., Todd, I. B., Gardiner, J. C., and Morrin, E. C. N., "Marine Mammal Observer and Passive Acoustic Monitoring Handbook", Pelagic Publishing Ltd, Exeter, UK. ISBN 978-1-907807-66-4, (2015). https://dx.doi.org/10.1111/mms.12290.

$10 \mathrm{Au}, \mathrm{W} . \mathrm{W}$. L., and Lammers, M. O., "Listening in the ocean : new discoveries and insights on marine life from autonomous passive acoustic recorders", Springer, New York, NY, (2016). https://dx.doi.org/10.1007/978-1-49393176-7.
11 Roberts, B. L., and Read, A. J., "Field assessment of C-POD performance in detecting echolocation click trains of bottlenose dolphins (Tursiops truncatus)", Mar. Mamm. Sci. 31, 169-190, (2015). https://dx.doi.org/10.1111/mms.12146.

12 Todd, V. L. G., Pearse, W. D., Tregenza, N. C., Lepper, P. A., and Todd, I. B., "Diel echolocation activity of harbour porpoises (Phocoena phocoena) around North Sea offshore gas installations," ICES J. Mar. Sci. 66, 734-745, (2009). https://dx.doi.org/10.1093/icesjms/fsp035.

13 Nuuttila, H. K., Courtene-Jones, W., Baulch, S., Simon, M., and Evans, P. G., "Don't forget the porpoise: acoustic monitoring reveals fine scale temporal variation between bottlenose dolphin and harbour porpoise in Cardigan Bay SAC”, Mar. Biol. 164, 50-66, (2017). https://dx.doi.org/10.1007/s00227-017-3081-5.

14 C-POD guide, "C-POD.exe: A guide for users," edited by N. Tregenza (Chelonia Ltd.), available at www.chelonia.co.uk, (2014).

15 Sostres Alonso, M., and Nuuttila, H. K., "Detection rates of wild harbour porpoises and bottlenose dolphins using static acoustic click loggers vary with depth", Bioacoustics 24, 1-10, (2014). https://dx.doi.org/10.1080/09524622.2014.980319.

16 Williamson, L., D, Brookes, K., L, Scott, B., E, Graham, I., M, and Thompson, P., "Diurnal variation in harbour porpoise detection - potential implications for management", Mar. Ecol. Prog. Ser. 570, 223-232, (2017). https://dx.doi.org/10.3354/meps12118.

17 Zimmer, W. M. X., "Passive Acoustic Monitoring of Cetaceans", Cambridge University Press, New York, United States of America, (2011). https://dx.doi.org/10.1017/CBO9780511977107.

18 Dunn, C. A., Tyack, P., Miller, P. J., and Rendell, L., "Short first click intervals in echolocation trains of three species of deep diving odontocetes," JASA 141, 900-907, (2017). https://dx.doi.org/10.1121/1.4976084.

19 Verfuß, U. K., Miller, L. A., Pilz, P. K., and Schnitzler, H. U., "Echolocation by two foraging harbour porpoises (Phocoena phocoena)," J. Exp.Biol. 212, 823-834, (2009). https://dx.doi.org/10.1242/jeb.022137.

20 Carlström, J., "Diel variation in echolocation of wild harbour porpoises," Mar. Mamm. Sci. 21, 1-12, (2005). https://dx.doi.org/10.1111/j.1748-7692.2005.tb01204.x.

21 Morozov, B. P., Akapiam, A. E., Burdin, V. I., Zaitseva, K. A., and Sokovykh, Y. A., "Tracking frequency of the location signals of dolphins as a function of distance to the target", Biofizika, 17, 139-145, (1972).

22 Wisniewska, D. M., Johnson, M., Beedholm, K., Wahlberg, M., and Madsen, P. T., "Acoustic gaze 
adjustments during active target selection in echolocating porpoises", J. Exp. Biol. 215, 4358-4373, (2012). https://dx.doi.org/10.1242/jeb.074013.

23 Benda-Beckmann, A.M.V., Thomas, L., Tyack, P.L., and Ainslie, M.A., "Modelling the broadband propagation of marine mammal echolocation clicks for click-based population density estimates", JASA 143, 954-967, (2018). https://dx.doi.org/10.1121/1.5023220.

24 Griffin, D. R., Webster, F. A., and Michael, C. R., "The echolocation of flying insects by bats," Anim. Behav. 8, 141-154, (1960). https://dx.doi.org/10.1016/00033472(60)90022-1.

25 Goodson, A., Klinowska, M., and Morris, R., "Interpreting the acoustic pulse emissions of a wild bottlenose dolphin (Tursiops truncatus)", Aquat. Mamm. 14, 7-12, (1988).

26 Carlström, J., Berggren, P., and Tregenza, N. J., "Spatial and temporal impact of pingers on porpoises", Can. J. Fish. Aquat. Sci. 66, 72-82, (2009). https://dx.doi.org/10.1139/F08-186.

27 Wisniewska, Danuta M., Johnson, M., Teilmann, J., Rojano-Doñate, L., Shearer, J., Sveegaard, S., Miller, Lee A., Siebert, U., and Madsen, Peter T., "Ultra-high foraging rates of harbor porpoises make them vulnerable to anthropogenic disturbance", Curr. Biol. 26, 1-6, (2016). https://dx.doi.org/10.1016/j.cub.2016.03.069.

28 Wingfield, J. E., O’Brien, M., Lyubchich, V., Roberts, J. J., Halpin, P. N., Rice, A. N., and Bailey, H., "Year-round spatiotemporal distribution of harbour porpoises within and around the Maryland wind energy area", 12, e:0176653, (2017). https://dx.doi.org/10.1371/journal.pone.0176653.

29 Scott, D. W.. "On optimal and data-based histograms", Biometrika 66, 605-610. (1979) https://dx.doi.org/10.1093/biomet/66.3.605.

30 Wand, M., "Data-based choice of histogram bin width", The American Statistician 51, 59-64, (1997). https://dx.doi.org/10.1080/00031305.1997.10473591.

31 Villadsgaard, A., Wahlberg, M., and Tougaard, J., "Echolocation signals of wild harbour porpoises, Phocoena phocoena," J. Exp. Biol. 210, 56-64, (2007). https://dx.doi.org/10.1242/jeb.02618.

32 SAMBAH, online (accessed 22/06/2017) http://www.sambah.org/SAMBAH-Final-Report-FINALfor-website-April-2017.pdf, (2017).

33 United States Naval Observatory, home web page, http://www.usno.navy.mil/USNO; in particular the Astronomical Applications Department web page http://aa.usno.navy.mil/data/docs/RS_OneYear.php, (2015).

34 Wardrop, R.L., "Statistics: Learning in the Presence of Variation", W.C. Brown publishers. ISBN-13: 978-0697215932. In particular, ISBN 978-0-697215-93-2, (1995).
35 Schaffeld, T., Bräger, S., Gallus, A., Dähne, M., Krügel, K., Herrmann, A., Jabbusch, M., Ruf, T., Verfuß, U. K., and Benke, H., "Diel and seasonal patterns in acoustic presence and foraging behaviour of free-ranging harbour porpoises", Mar. Ecol. Prog. Ser. 547, 257-272, (2016). https://dx.doi.org/10.3354/meps11627.

36 Teilmann, J., Miller, L. A., Kirketerp, T., Kastelein, R. A., Madsen, P. T., Nielsen, B. K., and Au, W. W. L., "Characteristics of echolocation signals used by a harbour porpoise (Phocoena phocoena) in a target detection experiment," Aquat. Mamm. 28, 275-284, (2002).

37 Verfuß, U. K., Miller, L. A., and Schnitzler, H. U., "Spatial orientation in echolocating harbour porpoises (Phocoena phocoena)," J. Exp. Biol. 208, 3385-3394, (2005). https://dx.doi.org/10.1242/jeb.01786.

38 Kastelein, R. A., Verlaan, M., and Jennings, N., "Number and duration of echolocation click trains produced by a harbor porpoise (Phocoena phocoena) in relation to target and performance," JASA 124, 40-43, (2008). https://dx.doi.org/10.1121/1.2924132.

39 DeRuiter, S. L., Bahr, A., Blanchet, M. A., Hansen, S. F., Kristensen, J. H., Madsen, P. T., Tyack, P. L., and Wahlberg, M., "Acoustic behaviour of echolocating porpoises during prey capture," J. Exp. Biol. 212, 3100-3107, (2009). https://dx.doi.org/10.1242/jeb.030825.

40 Akamatsu, T., Wang, D., Wang, K., Li, S., and Dong, S., "Scanning sonar of rolling porpoises during prey capture dives," J. Exp. Biol. 213, 146-152, (2010). https://dx.doi.org/10.1242/jeb.037655.

41 Amundin, M., "Sound production in odontocetes with emphasis on the harbour porpoise Phocoena phocoena," Department of Zoology, Division of Functional Morphology University of Stockholm, Sweden, p.128, (1991).

42 Clausen, K. T., Wahlberg, M., Beedholm, K., Deruiter, S., and Madsen, P. T., "Click communication in harbour porpoises Phocoena phocoena", Bioacoustics 20, 1-28, (2010). https://dx.doi.org/10.1080/09524622.2011.9753630.

43 Atem, A. C. G., Rasmussen, M. H., Wahlberg, M., Petersen, H. C., and Miller, L. A., "Changes in click source levels with distance to targets: studies of free-ranging white-beaked dolphins Lagenorhynchus albirostris and captive harbour porpoise Phocoena phocoena," Bioacoustics 19, 49-65, (2009). https://dx.doi.org/10.1080/09524622.2009.9753614.

44 Akamatsu, T., Hatakeyama, T., Kojima, H., and Soeda, H., "The rate at which harbour porpoise usess echolocation at night," Marine Mammal Sensory Systems, edited by J. A. Thomas, R. A. Kastelein, and A. Y. Supin (Plenum Press, New York), pp.299-315, (1992). https://dx.doi.org/10.1007/978-1-4615-3406-8_22. 